\title{
Linfadenopatia cervical na infância: etiologia, diagnóstico diferencial e terapêutica
}

Cervical lymphadenopathy in children: etiology, differential diagnosis and management

Leandro Luongo de Matos', Mario Paulo Faro Junior², Jossi Ledo Kanda', Vicente Antônio Gerardi Filho ${ }^{3}$ Pedro Muñoz Fernandes ${ }^{3}$

\section{Resumo}

Linfadenopatia é o termo empregado em qualquer alteração em tamanho e consistência de linfonodos. A linfadenopatia cervical é um problema muito frequente nos pacientes da faixa etária pediátrica e, em geral, representa reação transitória a processos inflamatórios ou infecciosos locorregionais ou sistêmicos. Porém, em uma pequena parcela, há neoplasias como fator etiológico. Na grande maioria das vezes, esses pacientes são efetivamente tratados pelo pediatra, porém, quando não há resposta à terapia inicial ou quando há suspeita de malignidade, 0 cirurgião pediátrico ou de cabeça e pescoço deve ser consultado. Este trabalho teve por objetivo revisar a etiologia, o diagnóstico diferencial e a terapêutica da linfadenopatia cervical na infância.

Palavras-chave: Doenças linfáticas; neoplasias de cabeça e pescoço; revisão.

\section{Abstract}

Lymphadenopathy refers to any alteration in size and consistency involving lymph nodes. Cervical lymphadenopathy is a very frequent problem in the pediatric group and, in general, represents a transitory reaction to locoregional or systemic inflammatory or infectious process. However, in a few cases, there is neoplasia as etiologic factor. Although most patients are successfully treated by their pediatrician, the pediatric or head and neck surgeon should be consulted for patients who fail to respond to initial therapy or for those in whom there is a suspiciousness of malignancy. The aim of this article was to review the etiology, the differential diagnosis, and the management of cervical lymphadenopathy in children.

Keywords: Lymphatic diseases; head and neck neoplasms; review.

Recebido: 14/10/2009

Revisado: $30 / 11 / 2009$

Aprovado: $15 / 1 / 2010$

\footnotetext{
Disciplina de Cirurgia de Cabeça e Pescoço da Faculdade de Medicina do ABC (FMABC), Santo André (SP), Brasil

2 Disciplina de Cirurgia Geral e de Urgência da FMABC, Santo André (SP), Brasil

${ }^{3}$ Disciplina de Cirurgia Pediátrica da FMABC, Santo André (SP), Brasil

Endereço para correspondência: Leandro Luongo de Matos - Avenida Lauro Gomes, 2.000 - CEP 09060-650 - Santo André (SP), Brasil -

E-mail: Imatos@amcham.com.br
} 


\section{Introdução}

Linfonodos cervicais palpáveis são extremamente comuns na infância ${ }^{1}$, presentes em até 38 a $45 \%$ das crianças normais ${ }^{2}$. Linfadenopatia cervical é o termo coletivo empregado no diagnóstico de linfonodos cervicais com mais de $1 \mathrm{~cm}$ de diâmetro, independentemente de suas características $^{3}$. Na maioria dos casos, representa resposta transitória secundária a processo infeccioso local ou até mesmo generalizado (sendo denominada de linfadenite). Ocasionalmente, pode ser evidência de malignidade ${ }^{1}$, sendo, então, importante o correto diagnóstico diferencial e terapêutica específica. Este trabalho teve por objetivo revisar a etiologia, o diagnóstico diferencial e a terapêutica da linfadenopatia cervical na infância.

\section{Anatomia e patofisiologia}

A drenagem linfática cervical segue um padrão bem estabelecido. Dessa forma, a localização da linfadenopatia é um bom indicador do sítio de agressão ao organismo, quando se trata de doença local da cabeça e pescoço (Figura 1) e não de doença sistêmica ${ }^{4}$. Em geral, o aumento de linfonodos superficiais remete a injúrias epiteliais (por exemplo, mucosas oral e nasal, pele etc.), enquanto os profundos representam o envolvimento de estruturas mais centrais (por exemplo, orelha média, faringe posterior etc. $)^{1}$.

Linfadenopatias são causadas pela proliferação de células intrínsecas do linfonodo (como linfócitos, células plasmáticas, monócitos ou histiócitos) ou pela infiltração por células extrínsecas (como neutrófilos ou células malignas $)^{5}$.

\section{Avaliação clínica}

A correta abordagem propedêutica é crucial na avaliação de linfadenopatias cervicais. Anamnese e exame físico detalhados fornecem dados que são fundamentais para o correto diagnóstico, como discutido a seguir.

\section{Anamnese}

- Idade: alguns micro-organismos têm predileção por determinada faixa etária (Quadro 1), e também há prevalência de diferentes tipos de neoplasias de acordo com a idade ${ }^{5}$.

- Lateralidade e cronicidade: linfadenite cervical aguda bilateral é usualmente causada por infecção viral do trato respiratório superior ou faringite estreptocócica ${ }^{1}$. A linfadenopatia cervical na doença de Kawasaki é, em geral, unilateral. Linfadenite cervical aguda unilateral é causada por infecções estreptocócicas ou estafilocócicas em 40 a $80 \%$ dos $\operatorname{casos}^{5,6}$. As principais causas de linfadenite subaguda ou crônica são: doença da arranhadura do gato, infecções por micobactérias e toxoplasmose; as causas menos frequentes são: infecções por citomegalovírus e vírus Epstein-Barr ${ }^{1,7}$.

- Sintomas associados: febre, tosse e odinofagia indicam infecção do trato respiratório superior. Febre, tremores noturnos e perda de peso são sugestivos de tuberculose ou linfoma. Doenças vasculares e do colágeno ou imunossupressão devem ser pesquisadas quando há febre de origem indeterminada, fadiga e artralgia ${ }^{1,8}$.

- Antecedentes pessoais: tonsilite prévia sugere infecção estreptocócica; escoriações recentes em face ou pescoço indicam infecção estafilocócica; infecção periodontal pode indicar um micro-organismo anaeróbico. Quando há história de arranhadura de gato, existe a possibilidade de infecção pela Bartonella henselae. Linfadenopatias como resultado de infecção pelo HIV, citomegalovírus ou vírus Epstein-Barr são encontrados em pacientes com passado transfusional positivo ${ }^{7}$. Linfadenopatia relacionada à imunização pode ser secundária à tríplice bacteriana, poliomielite ou febre tifoide?. Exposição a pessoas com infecções do trato respiratório superior, faringite estreptocócica ou tuberculose sugerem a doença correspondente ${ }^{1,9}$.

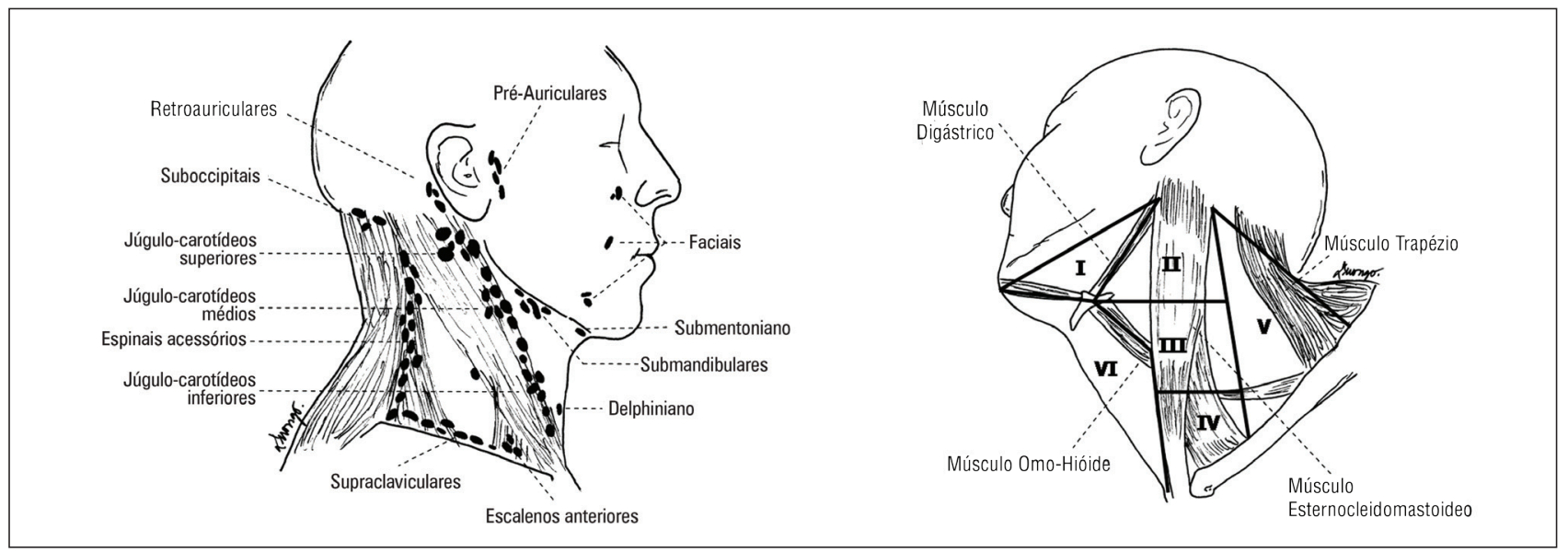

Figura 1 - Distribuição de linfonodos na região da cabeça e pescoço. I: linfonodos submentonianos e submandibulares; II: grupamento júgulocarotídeo superior; III: grupamento júgulo-carotídeo médio, responsáveis pela drenagem linfática da nasofaringe e orofaringe, cavidade oral, hipofaringe e laringe; IV: grupamento júgulo-carotídeo inferior, responsável pela drenagem linfática da hipofringe, laringe supraglótica, tireoide e esôfago; V: triângulo posterior; Vl: compartimento central'4. 
- Hábitos: a linfadenopatia pode ser secundária ao uso de fenitoína ou isoniazida ${ }^{10}$. Resposta a antibióticos específicos também pode ajudar a confirmar ou afastar diagnósticos ${ }^{1,10}$.

\section{Exame físico}

- Geral: Desnutrição ou distúrbios de crescimento sugerem doenças crônicas como tuberculose, malignidade ou imunodeficiência ${ }^{1}$.

- Características linfonodais específicas: todas as áreas com concentração de linfonodos palpáveis devem ser examinadas no intuito de verificar se a linfadenopatia é generalizada. Os linfonodos palpáveis devem ser medidos para comparações futuras. Dor, eritema, temperatura, mobilidade, presença de flutuação e consistência devem obrigatoriamente ser pesquisados ${ }^{11}$.

A linfadenite cervical aguda posterior é classicamente observada em indivíduos com rubéola ou mononucleose infecciosa. Linfadenopatias cervicais supraclaviculares ou posteriores representam um risco muito maior de malignidade quando comparadas às anteriores ${ }^{12}$. Já as associadas à linfadenopatia generalizada são frequentemente causadas por infecção viral, porém diagnósticos como leucemias, linfomas, doenças reumatológicas (por exemplo, artrite reumatoide juvenil, lupus eritematoso sistêmico etc.) e uso de medicamentos devem também ser pesquisados $^{1,12}$.

Nas linfadenopatias cervicais resultantes de infecções virais, os linfonodos são frequentemente bilaterais, fibroelásticos e não se encontram fixos a planos profundos. Quando há a presença de infecção bacteriana, esses geralmente são dolorosos, uni ou bilaterais e não-fixos. Eritema e aumento local de temperatura sugerem infecção aguda, e a presença de flutuação indica formação de abscesso. Em pacientes com tuberculose, os linfonodos podem ser coalescentes e flutuantes, e a pele ao redor pode apresentar-se com hiperemia, mas, em geral, não há aumento local de temperatura ${ }^{13}$.

Na linfadenopatia como resultado de infiltração por células malignas, sinais de inflamação aguda estão ausentes, e os linfonodos encontram-se em geral endurecidos e aderidos a tecidos profundos ${ }^{1}$.

- Sinais clínicos associados: hiperemia de orofaringe, exsudato purulento em tonsilas palatinas, petéquias em palato duro e língua em framboesa sugerem infecção por Streptococcus do grupo A. A difteria está associada a edema de partes moles do pescoço. Trajetos fistulosos de drenagem podem ser observados na tuberculose. A presença de gengivoestomatite sugere infecção pelo vírus Herpes simplex e herpangina pelo vírus Coxsackie. Na presença de faringite, rash maculopapular e esplenomegalia deve-se pesquisar infecção pelo vírus Epstein-Barr. Conjuntivite e manchas de Koplik são características de rubéola. Presença de palidez, petéquias, equimoses, dores retroesternais e hepatoesplenomegalia sugerem diagnóstico de leucemia. Febre prolongada, infecções conjuntivais, inflamação da mucosa da orofaringe, edema ou eritema periféricos e rash polimórfico corroboram o diagnóstico de doença de Kawasaki ${ }^{1,8}$.
Quadro 1 - Predileção de micro-organismos pela faixa etária ${ }^{5}$

\begin{tabular}{|c|c|}
\hline Faixa Etária & Micro-organismos \\
\hline \multirow[t]{2}{*}{ Neonatos } & Staphylococcus aureus \\
\hline & Streptococcus do grupo B \\
\hline \multirow[t]{2}{*}{ Até 1 ano } & Staphylococcus aureus \\
\hline & Streptococcus do grupo B \\
\hline \multirow[t]{3}{*}{1 a 4 anos } & Staphylococcus aureus \\
\hline & Streptococcus $\beta$ - hemolítico do grupo $\mathrm{A}$ \\
\hline & Micobactéria atípica \\
\hline \multirow[t]{4}{*}{5 a 15 anos } & Bactérias anaeróbicas \\
\hline & Toxoplasmose \\
\hline & Doença da arranhadura do gato \\
\hline & Tuberculose \\
\hline
\end{tabular}

\section{Avaliação laboratorial}

Exames laboratoriais, na maioria dos casos, não são necessários na avaliação de linfadenopatias cervicais. Como visto, dados de anamnese e exame físico têm bastante acurácia no diagnóstico da correta etiologia do aumento de volume linfonodal.

O leucograma auxilia no diagnóstico de linfadenite bacteriana; em geral, observa-se leucocitose em alguns casos com desvio à esquerda e presença de granulações tóxicas. Linfocitose atípica é bastante sugestiva de mononucleose infecciosa. Pancitopenia ou presença de blastos sugerem leucemia ${ }^{1,11}$.

A velocidade de hemossedimentação (VHS) é, em geral, bastante elevada nas linfangites bacterianas. Culturas de secreção de orofaringe ou tonsilas podem ser úteis na confirmação de infecção estreptocócica. Testes cutâneos para tuberculose (PPD) devem ser realizados quando há suspeita dessa infecção ${ }^{1,14}$.

Outros exames também podem corroborar o diagnóstico etiológico, o que inclui radiografia simples de tórax, testes sorológicos para Bartonella henselae quando há suspeita de doença da arranhadura do gato, sorologias para EBV, citomegalovírus e toxoplasmose'. Eletrocardiograma e ecocardiograma são indicados quando há suspeita de doença de Kawasaki ${ }^{15}$.

A ultrassonografia cervical é uma ferramenta diagnóstica de grande importância. Trata-se de exame inócuo, que fornece informações detalhadas quanto à ecotextura e forma dos linfonodos cervicais e também possibilita a visibilização da vascularização intranodal quando o exame é associado ao Doppler colorido ${ }^{16-19}$. A mensuração do maior e menor eixo axial do linfonodo e sua respectiva relação (L/S) é de grande valia: considera-se a relação $\mathrm{L} / \mathrm{S}>2$ como um critério muito sensível de benignidade, maior que a relação $\mathrm{L} / \mathrm{S}<2$, de malignidade ${ }^{20}$.

A ultrassonografia e a tomografia computadorizada auxiliam no diagnóstico diferencial entre massas císticas e sólidas cervicais e também na avaliação de supurações e infiltrações ${ }^{1}$.

A punção aspirativa por agulha fina (PAAF) do linfonodo e a solicitação de bacterioscopia (coloração de gram e álcool-ácido resistentes) e cultura (para bactérias aeróbicas e anaeróbicas, micobac- 
terias e fungos) são procedimentos factíveis na tentativa de isolar o agente infeccioso e determinar a adequada terapêutica antibiótica ${ }^{1,21}$.

A biópsia excisional (realizada no maior e mais representativo linfonodo palpável, que deve ser removido preferencialmente intacto e com a cápsula) e o exame microscópico podem ser necessários quando há dúvida diagnóstica, sinais e sintomas de malignidade ou persistência de linfadenopatia ou seu aumento, mesmo na vigência de terapêutica apropriada ${ }^{1,22}$.

\section{Etiologia}

As causas mais frequentes de linfadenopatias cervicais são listadas no Quadro 2. A etiologia mais comum é a hiperplasia reacional, resultante de um processo infeccioso, mais comumente uma infecção viral do trato respiratório superior ${ }^{6}$, como, por exemplo, rhinovirus, parainfluenza vírus, influenza vírus, vírus sincicial respiratório, coronavírus,

Quadro 2 - Causas de linfadenopatias cervicais ${ }^{1}$

\begin{tabular}{|c|c|}
\hline Tipo de Infecções & Agente ou doença \\
\hline \multirow[t]{7}{*}{ Bacterianas } & Staphylococcus aureus \\
\hline & Streptococcus $\beta$-hemolítico do grupo-A \\
\hline & Anaeróbios \\
\hline & Difteria \\
\hline & Doença da arranhadura do gato \\
\hline & Micobactérias atípicas \\
\hline & Tuberculose \\
\hline \multirow[t]{9}{*}{ Virais } & Infecções virais de vias aéreas superiores \\
\hline & Epstein-Barr vírus \\
\hline & Cytomegalovirus \\
\hline & Rubella \\
\hline & Rubéola \\
\hline & Varicella-zoster vírus \\
\hline & Herpes simplex \\
\hline & Coxsackievirus \\
\hline & HIV \\
\hline \multirow[t]{2}{*}{ Protozoários } & Doença de Chagas \\
\hline & Toxoplasmose \\
\hline \multirow[t]{2}{*}{ Parasitas } & Miíase \\
\hline & Pediculose \\
\hline \multirow[t]{2}{*}{ Fungos } & Paracocidiodomicose \\
\hline & Histoplasmose \\
\hline \multirow[t]{5}{*}{ Neoplasias } & Neuroblastoma \\
\hline & Leucemias \\
\hline & Linfomas \\
\hline & Rabdomiossarcoma \\
\hline & Metástases \\
\hline \multirow[t]{8}{*}{ Outros } & Doença de Kawasaki \\
\hline & Doenças de depósito \\
\hline & Artrite reumatoide \\
\hline & Doença do soro \\
\hline & Drogas \\
\hline & Pós-vacinação \\
\hline & Doença de Rosai-Dorfman \\
\hline & Doença de Kikuchi-Fujimoto \\
\hline
\end{tabular}

adenovírus ou reovírus. Outros vírus associados a linfadenopatias cervicais incluem: Epstein-Barr, citomegalovírus, rubella, rubéola, vírus da varicella-zoster, herpes simplex, coxsackievirus e o vírus da imunodeficiência humana (HIV) ${ }^{1,23}$.

Linfadenite bacteriana aguda é principalmente causada pelo Streptococcus $\beta$-hemolítico do grupo A ou Staphylococcus aureus. Bactérias anaeróbicas podem também causar linfadenite cervical, em geral associadas a cáries dentárias ou doenças periodontais. Streptococcus do grupo B e o Haemophilus influenzae tipo B são bactérias bem infrequentes, o que inclui também a difteria ${ }^{7}$. Bartonella hanselae (agente etiológico da doença da arranhadura do gato), micobactéria atípica e a própria micobactéria são causas importantes de linfadenopatia subaguda ou crônica ${ }^{13}$. Linfadenite cervical crônica posterior é a forma mais comum de toxoplasmose adquirida e trata-se de sintoma isolado em até $50 \%$ dos $\operatorname{casos}^{7}$.

Mais de $25 \%$ dos tumores malignos na infância originam-se na região da cabeça e pescoço, e os linfonodos cervicais são o sítio mais comum $^{1}$. Nos primeiros seis anos de vida, o neuroblastoma e a leucemia são os tumores mais associados a linfadenopatia cervical, seguidos do rabdomiossarcoma e o linfoma não-Hogdkin ${ }^{11}$. Entretanto, após os seis anos, o linfoma de Hogdkin é o mais frequente, seguido do linfoma não-Hogdkin e do rabdomiossarcoma ${ }^{11}$.

A presença de linfadenopatia cervical é um dos cinco critérios diagnósticos da doença de Kawasaki. Os outros quatro são: conjuntivite bilateral, alterações da mucosa da orofaringe, eritema ou edema de extremidades e rash cutâneo polimórfico. Linfadenopatia generalizada pode ser um indicativo de comprometimento sistêmico da artrite reumatoide juvenil, lupus eritematoso sistêmico ou doença do soro ${ }^{15}$.

Alguns medicamentos, especialmente a isoniazida e a fenitoína, podem causar linfadenopatia generalizada ${ }^{10}$, que também pode ser consequência de imunizações, tais como tríplice bacteriana, poliomielite e febre tifoide?

A doença de Rosai-Dorfman é uma forma benigna da histiocitose, caracterizada pela proliferação generalizada de histiócitos. A doença manifesta-se usualmente na primeira década de vida com linfadenopatia cervical dolorosa e múltipla, acompanhada de febre, leucocitose neutrofílica e hipergamaglobulinemia policlonal ${ }^{24}$. Já a doença de Kikuchi-Fujimoto (ou linfadenite necrotizante) é uma forma também benigna de linfadenopatia que afeta principalmente jovens femininas de origem japonesa, cujos sintomas sistêmicos incluem febre, náuseas, sudorese noturna, artralgia e hepatoesplenomegalia ${ }^{25,26}$.

\section{Diagnóstico diferencial}

Massas cervicais são comuns na infância e deve-se sempre pensar no aumento de linfonodos cervicais ${ }^{11}$. Os principais diagnósticos diferenciais das linfadenopatias cervicais encontram-se resumidos no Quadro 3.Em geral, as lesões congênitas encontram-se presentes desde 
o nascimento ou são diagnosticas logo após ${ }^{27}$. Os aspectos clínicos que auxiliam na diferenciação entre várias condições e as linfadenopatias cervicais são discutidas a seguir.

\section{Caxumba}

O edema da parótida, aumentada pelo processo inflamatório da caxumba, pode cruzar o ângulo da mandíbula. Por outro lado, linfonodos cervicais são usualmente encontrados na região submandibular ${ }^{28}$.

\section{Cisto tireoglosso}

Caracteriza-se por tumor cístico palpável na linha média cervical e apresenta mobilidade à deglutição ou à protrusão da língua ${ }^{29}$.

\section{Remanescentes branquiais}

Quando se apresentam como cistos são encontrados na região pré-auricular (anomalias da primeira fenda branquial), ao longo da borda anterior do músculo esternocleidomastoideo (anomalias da segunda, terceira e quarta fendas branquiais) ${ }^{1}$.

\section{Tumor do músculo esternocleidomastoideo}

Caracteriza-se por tumor endurecido, que se move no sentido laterolateral, mas não craniocaudal, que acompanha o ventre do músculo esternocleidomastoideo, resultado de hemorragia intramuscular do período perinatal e que posteriormente é substituída por fibrose. A presença de torcicolo é frequente ${ }^{30}$.

\section{Costela cervical}

Anomalia ortopédica que é, em geral, bilateral, endurecida e imóvel. O diagnóstico é estabelecido pela radiografia cervical ${ }^{1,31}$.

\section{Higroma cístico}

Tipo especial de linfangioma com grandes cistos. Apresenta-se multiloculado, difuso, fibroelástico e compressível; formado por linfa, tipicamente apresenta transluminescência positiva ${ }^{32}$.

\section{Hemangioma}

Anomalia congênita vascular que frequentemente encontra-se presente ao nascimento ou logo após. A massa é, em geral, avermelhada e azulada ${ }^{32}$.

\section{Laringocele}

Massa cística compressível, que se estende da laringe à membrana tireoidea e que aumenta com a manobra de Valsalva. Pode haver associação com estridor laríngeo ou disfonia e, em geral, a radiografia cervical mostra o contorno aéreo do cisto $^{32}$.

\section{Cisto dermoide}

Cisto com componente em geral sólido-cístico que pode apresentar transluminescência positiva e calcificações à radiografia ${ }^{32}$.
Quadro 3 - Diagnóstico diferencial de linfadenopatias cervicais

\begin{tabular}{|l|}
\hline Caxumba \\
Cisto tireoglosso \\
Remanescentes branquiais \\
Tumor do músculo esternocleidomastoideo \\
Costela cervical \\
Higroma cístico \\
Hemangioma \\
Laringocele \\
Cisto dermoide \\
Outros \\
Teratomas \\
Neoplasias da tireoide \\
Neoplasias de glândulas salivares \\
Cistos tímicos \\
Cistos de paratireoide \\
\hline
\end{tabular}

\section{Terapêutica}

O tratamento da linfadenopatia cervical depende da causa específica. A maioria dos casos são autolimitados e não requerem tratamento, apenas observação ${ }^{1}$. Falha na regressão após quatro a seis semanas pode ser indicativa de biópsia diagnóstica 5 .

O tratamento da linfadenite cervical bacteriana aguda sem um foco de infecção primário conhecido deve prover adequada cobertura antibiótica para Staphilococcus aureus e Streptococcus $\beta$-hemolítico do grupo A. Antibióticos orais incluem amoxaciclina, cefalexina ou clindamicina ${ }^{6}$. Quando um foco primário de infecção é identificado, a terapêutica deve ser direcionada empiricamente ao agente etiológico mais frequentemente associado à doença, sendo que resultados de culturas e antibiogramas são fundamentais ${ }^{1}$. Crianças com linfadenopatia cervical e doença dentária ou periodontal devem ser tratadas com penicilina ou clindamicina ${ }^{6}$. É importante ressaltar que, em crianças imunocomprometidas, sépticas ou nas quais a antibioticoterapia oral não seja efetiva, deve-se avaliar a necessidade de terapêutica parenteral ${ }^{6}$. Caso haja a presença de flutuação, deve-se avaliar a necessidade de drenagem cirúrgica ${ }^{1}$.

A recomendação atual para o tratamento da linfadenite tuberculosa cervical isolada é o esquema tríplice com isoniazida, rifampicina e pirazinamida nos primeiros 1 a 2 meses (em alguns casos, há necessidade da associação de etambutol, estreptomicina ou outro aminoglicosídeo ou etionamida), seguido de isonizida e rifampicina por 6 a 12 meses $^{33}$. Linfadenite por micobactéria atípica não costuma responder à terapêutica antibiótica convencional (em geral, emprega-se macrolídeos), sendo necessária a excisão de todos os linfonodos visualmente acometidos $^{6,34}$.

O controle dos sintomas deve também ser empregado. Para tal, podem ser utilizados analgésicos e anti-inflamatórios não-esteroidais. 
Algoritmos terapêuticos para casos de linfadenopatias generalizadas foram propostos e aplicados ${ }^{21}$. Entretanto, para a linfadenopatia cervical específica da população pediátrica existe uma série de guidelines, sem que haja um consenso claro estabelecido 3 .
A biópsia é indicada nas seguintes situações ${ }^{35}$ : linfonodos maiores que $3 \mathrm{~cm}$, presentes por mais de seis semanas; linfonodos maiores que 3 $\mathrm{cm}$ que continuam crescendo após dois meses; massas ganglionares com linfonodos endurecidos e confluentes; linfonodos supraclaviculares.

\section{Referências}

1. Leung AK, Robson WL. Childhood cervical lymphadenopathy. J Pediatr Health Care. 2004;18(1):3-7.

2. Larsson LO, Bentzon MW, Berg Kelly K, Mellander L, Skoogh BE, Strannegård IL et al. Palpable lymph nodes of the neck in Swedish schoolchildren. Acta Paediatr. 1994;83(10):1091-4.

3. Niedzielska G, Kotowski M, Niedzielski A, Dybiec E, Wieczorek P. Cervical lymphadenopathy in children--incidence and diagnostic management. Int $J$ Pediatr Otorhinolaryngol. 2007;71(1):51-6.

4. Marur S, Forastiere AA. Head and neck cancer: changing epidemiology, diagnosis, and treatment. Mayo Clin Proc. 2008;83(4):489-501.

5. Chesney PJ. Cervical adenopathy. Pediatr Rev. 1994;15(7):276-84.

6. Peters TR, Edwards KM. Cervical lymphadenopathy and adenitis. Pediatr Rev. 2000;21(12):399-405

7. Gosche JR, Vick L. Acute, subacute, and chronic cervical lymphadenitis in children. Semin Pediatr Surg. 2006;15(2):99-106.

8. Ciambra R, Milocco C, Facchini S, Leone V, Locatelli C, Pocecco M. Periodic fever, aphthous stomatitis, pharyngitis, and lymphadenopathy: a pediatric caseload. Pediatr Med Chir. 2003;25(3):181-4

9. Falkensammer B, Walder G, Busch D, Giessauf A, Dierich M, Würzner R. Epidemiology of rubella infections in Austria: important lessons to be learned. Eur J Clin Microbiol Infect Dis. 2004;23(6):502-5

10. Scheinfeld N. Impact of phenytoin therapy on the skin and skin disease. Expert Opin Drug Saf. 2004;3(6):655-65.

11. Tracy TF Jr, Muratore CS. Management of common head and neck masses. Semin Pediatr Surg. 2007;16(1):3-13.

12. Soldes OS, Younger JG, Hirschl RB. Predictors of malignancy in childhood peripheral lymphadenopathy. J Pediatr Surg. 1999;34(10):1447-52.

13. Spyridis P, Maltezou HC, Hantzakos A, Scondras C, Kafetzis DA Mycobacterial cervical lymphadenitis in children: clinical and laboratory factors of importance for differential diagnosis. Scand $\mathrm{J}$ Infect Dis. 2001;33(5):362-6.

14. Patel NC, Minifee PK, Dishop MK, Munoz FM. Mycobacterium simiae cervical lymphadenitis. Pediatr Infect Dis J. 2007;26(4):362-3.

15. Yanagi S, Nomura Y, Masuda K, Koriyama C, Sameshima K, Eguchi $T$ et al. Early diagnosis of Kawasaki disease in patients with cervical lymphadenopathy. Pediatr Int. 2008;50(2):179-83.

16. Giovagnorio F, Caiazzo R, Avitto A. Evaluation of vascular patterns of cervical lymph nodes with power Doppler sonography. J Clin Ultrasound 1997;25(2):71-6.
17. Tschammler A, Ott G, Schang T, Seelbach-Goebel B, Schwager K, Hahn D. Lymphadenopathy: differentiation of benign from malignant disease-color Doppler US assessment of intranodal angioarchitecture. Radiology. 1998:208(1):117-23

18. Na DG, Lim HK, Byun HS, Kim HD, Ko YH, Baek JH. Differential diagnosis of cervical lymphadenopathy: usefulness of color Doppler sonography. AJP Am J Roentgenol. 1997;168(5):1311-6.

19. Wu CH, Chang YL, Hsu WC, Ko JY, Sheen TS, Hsieh FJ. Usefulness of Doppler spectral analysis and power Doppler sonography in the differentiation of cervical lymphadenopathies. AJR Am J Roentgenol. 1998;171(2): 503-9.

20. Vassallo P, Edel G, Roos N, Naguib A, Peters PE. In-vitro high-resolution ultrasonography of benign and malignant lymph nodes. A sonographicpathologic correlation. Invest Radiol. 1993;28(8):698-705.

21. Umapathy N, De R, Donaldson I. Cervical lymphadenopathy in children. Hosp Med. 2003;64(2):104-7

22. Tiwari M, Aryal G, Shrestha R, Rauniyar SK, Shrestha HG. Histopathologic diagnosis of lymph node biopsies. Nepal Med Coll J. 2007;9(4):259-61.

23. Prasad HK, Bhojwani KM, Shenoy V, Prasad SC. HIV manifestations in otolaryngology. Am J Otolaryngol. 2006;27(3):179-85.

24. Gupta P, Babyn P. Sinus histiocytosis with massive lymphadenopathy (Rosai-Dorfman disease): a clinicoradiological profile of three cases including two with skeletal disease. Pediatr Radiol. 2008;38(7): 721-8.

25. Thongsuksai P, Kayasut K. Histiocytic necrotizing lymphadenitis (Kikuchi's disease): clinicopathologic characteristics of 23 cases and literature review. J Med Assoc Thai. 1999;82(8):812-8.

26. Lazzareschi I, Barone G, Ruggiero A, Liotti L, Maurizi P, Larocca LM et al. Paediatric Kikuchi-Fujimoto disease: a benign cause of fever and lymphadenopathy. Pediatr Blood Cancer. 2008;50(1):119-23.

27. Twist CJ, Link MP. Assessment of lymphadenopathy in children. Pediatr Clin North Am. 2002;49(5):1009-25

28. Myer C, Cotton RT. Salivary gland disease in children: a review. Part 1: Acquired non-neoplastic disease. Clin Pediatr (Phila). 1986;25(6):314-22.

29. Shrestha SK, Sharma VK. Thyroglossal duct remnant: seven years analysis JNMA J Nepal Med Assoc. 2006;45(161):178-81.

30. Bredenkamp JK, Maceri DR. Inflammatory torticollis in children. Arch Otolaryngol Head Neck Surg. 1990;116(3):310-3

31. Mangrulkar VH, Cohen HL, Dougherty D. Sonography for diagnosis of cervical ribs in children. J Ultrasound Med. 2008:27(7):1083-6. 
32. Imhof $\mathrm{H}$, Czerny $\mathrm{C}$, Hörmann $\mathrm{M}$, Krestan $\mathrm{C}$. Tumors and tumor-like lesions of the neck: from childhood to adult. Eur Radiol. 2004;14 Suppl 4:L155-65.

33. Wei YF, Liaw YS, Ku SC, Chang YL, Yang PC. Clinical features and predictors of a complicated treatment course in peripheral tuberculous lymphadenitis. J Formos Med Assoc. 2008;107(3):225-31.
34. Hazra R, Robson CD, Perez-Atayde AR, Husson RN. Lymphadenitis due to nontuberculous mycobacteria in children: presentation and response to therapy. Clin Infect Dis. 1999;28(1):123-9.

35. Marchese LT. Linfadenites cervicais. In: Maksoud JG, editor. Cirurgia pediátrica. Rio de Janeiro: Revinter; 2003. v. 1. p. 403. 